\title{
Low-cost disposable endoscope: pros and cons
}

\section{(ㄷ)(1) $(9)$}

\author{
Author \\ Mihai Ciocîrlan \\ Institution \\ "Carol Davila" University of Medicine and Pharmacy, \\ “Agrippa Ionescu” Clinical Emergency Hospital, Bucharest, \\ Romania \\ Bibliography \\ DOI https://doi.org/10.1055/a-0959-6003 | \\ Endoscopy International Open 2019; 07: E1184-E1186
}

Keith Obstein and collaborators from the Vanderbilt University, United States, have designed and developed a low-cost \$35 disposable endoscope [1]. This endoscope uses a joystick-like driving mechanism which controls the endoscope tip. Their team proved its feasibility in examining the esophagus and the stomach of an ex-vivo phantom model. Unexperienced users had similar performance using a conventional scope and the new disposable scope and favor the later.

Conventional endoscopes have high acquisition costs 20,000 to $\$ 40,000$ for an upper endoscopy or colonoscopy tube and around $\$ 80,000$ to $\$ 120,000$ for a complete twotube working system to explore both the upper and the lower gastrointestinal tract. Costs for an additional endoscopic ultrasound system are in the range of $\$ 200,000$.

Use of conventional scopes requires higher levels of continuous training and skills, both for physicians and endoscopy nurses, especially for therapeutic procedures. The American Society of Gastrointestinal Endoscopy (ASGE) training recommendations and competence evaluation include both quantitative and detailed qualitative examination criteria [2].

The workload, costs. and staff hazards associated with reprocessing conventional endoscopes are significant, and costs range between $\$ 140$ and $\$ 280$ per endoscope $[3,4]$. Non-adherence to endoscope reprocessing guidelines together with failure to perform periodic maintenance and auditing may lead to cross-contamination [3]. In light of these disadvantages, there are potential advantages of using disposable endoscopes ( $\triangleright$ Table 1). Available single-use disposable scopes are listed presented in $>$ Table $2[5,6]$.

The PrimeSight TNE-500 esophagoscope was discontinued in April 2018, the day that the Cogentix company was acquired by Laborie company [7]. This was not a disposable scope, but was only covered by a single-use plastic sheet (EndoSteath). A sheet version with a working channel for biopsy capability was also available. Several clinical studies were published using this esophagoscope, mainly for Barrett esophagus screening and surveillance. The cost of one EndoSheath was around $\$ 40$.

E.G. II is a South Korean disposable $\$ 100$ scope with the capability of examining the esophagus and partly the stomach and duodenum. There is no working channel with biopsy capability. The device is commercially available.

Ambu company, the Danish manufacturer of disposable ear, nose and throat scopes and bronchoscopes, projected the launch of disposable upper and lower gastrointestinal scopes by 2020 [8]. The current price for one disposable bronchoscope is $\$ 350$. Disposable robotics colonoscopy systems are listed in - Table 3.

Available human studies were done on approximately 100 patients before the year 2013 and no other data have become available since [9-11]. There are no published data on their use outside their initial development centers.

Cecal intubation rates for Aer-O-Scope, Endotics System and Invendoscope were $98.2 \%, 93.1 \%$ and $98.4 \%$, respectively, and mean time to reach the cecum was 14 minutes, 51 minutes, and 15 minutes, respectively.

Table 1 Comparative analysis of reusable and single-use endoscopes.

\begin{tabular}{|l|l|}
\hline Reusable endoscopes & Single-use endoscopes \\
\hline High acquisition costs & Lower acquisition costs \\
\hline Higher level of training and skills & Lower level of training and skills \\
\hline $\begin{array}{l}\text { High reprocessing costs } \\
\text { (disinfection, surveillance, } \\
\text { maintenance, repair) }\end{array}$ & No reprocessing costs \\
\hline Risk of cross-contamination & No risk of cross-contamination \\
\hline Impact on the environment? & Impact on the environment? \\
\hline
\end{tabular}


- Table 2 Currently available disposable endoscopes.

\begin{tabular}{|c|c|c|c|}
\hline Disposable scope name & $\begin{array}{l}\text { PrimeSight TNE-500 esophago- } \\
\text { scope (with EndoSheath) }\end{array}$ & E.G. II & aScope \\
\hline Manufacturer & $\begin{array}{l}\text { Laborie, Canada (acquired Cogen- } \\
\text { tix, United States, in 2018) }\end{array}$ & IntroMedic, South Korea & $\begin{array}{l}\text { Ambu, Denmark (acquired Invendo Medical, } \\
\text { Germany, in 2017) }\end{array}$ \\
\hline Availability & Discontinued [5] & Available & Projected in 2020 [6] \\
\hline Outer diameter & $\begin{array}{l}4.7 \mathrm{~mm} \text { and } 5.4 \mathrm{~mm} \text { (with working } \\
\text { channel) }\end{array}$ & $4 \mathrm{~mm}$ & $6.2 \mathrm{~mm}, 5.4 \mathrm{~mm}, 4.2 \mathrm{~mm}^{1}$ \\
\hline Bending & 2-way & 2 way & 2 way $^{1}$ \\
\hline Bending angle & $215^{\circ}$ up and $140^{\circ}$ down & $210^{\circ}$ up and down & $180^{\circ}$ up and $180^{\circ}$ down ${ }^{1}$ \\
\hline Length & $650 \mathrm{~mm}$ & $1022 \mathrm{~mm}$ & $600 \mathrm{~mm}^{1}$ \\
\hline Air inflation & Yes & Yes & Probably \\
\hline Suction channel & Yes & No & Yes $^{1}$ \\
\hline Biopsy capability & Yes & No & Yes $^{1}$ \\
\hline Explores & Esophagus & $\begin{array}{l}\text { Esophagus and partially the } \\
\text { stomach and duodenum }\end{array}$ & $\begin{array}{l}\text { Upper and lower gastrointestinal tract; an } \\
\text { ERCP solution is also developed. }\end{array}$ \\
\hline Cost of the disposable part & Sheath $\$ 40$ & Endoscope $\$ 100$ & $\$ 350^{1}$ \\
\hline $\begin{array}{l}\text { Cost of the non-disposable } \\
\text { part }\end{array}$ & System with endoscope $\$ 11,650$ & System $\$ 15,000$ & aView monitor $\$ 2600$ \\
\hline Feasibility studies & [5] & {$[6]$} & Over 50 studies for bronchoscopy and ENT \\
\hline
\end{tabular}

- Table 3 Currently available robotic disposable colonoscopes.

\begin{tabular}{|l|l|l|l|}
\hline $\begin{array}{l}\text { Robotic disposable colonos- } \\
\text { copy name }\end{array}$ & Aer-O-Scope & Endotics System & Invendoscope SC210 \\
\hline Manufacturer & GI View, Israel & Endotics, Italy & $\begin{array}{l}\text { Ambu, Denmark (acquired Invendo } \\
\text { Medical, Germany, in 2017) }\end{array}$ \\
\hline Availability & $\begin{array}{l}\text { Current version unavailable. New } \\
\text { version projected for } 2020 .\end{array}$ & $\begin{array}{l}\text { Unknown, possibly } \\
\text { available }\end{array}$ & Available \\
\hline Features & Two working channels & One working channel & One working channel \\
\hline Cost of the disposable part & Target projected price $\$ 250$ & Unknown & $\$ 350$ \\
\hline Cost of the non-disposable part & Target projected price $\$ 15,000$ & Unknown & Invendo SPU E210, quote on demand. \\
\hline
\end{tabular}

The Invendoscope SC210 version is available for purchase for $\$ 350$ together with the Invendo E210 guiding system. A new version of Aer-O-Scope has been tested and is projected to be marketed in 2020.

Returning to $>$ Table 1, one of the concerns with low-cost disposable scopes may be plastic pollution. This may be an issue for the future as it recently has been shown that plastic microparticles may be traced in stools of humans around the globe [12]. EU has recently tackled this issue and banned single-use plastics [13].

A disruptive technology could change the face of endoscopy as we know it. Low-cost video-capsules or nanorobots with possibility of biopsy, tagging, and therapy may appear sometime. In the meantime, our core business is endoscopy and we should strive to improve it, maybe by transitioning to single-use instruments. For the moment, there is no way to predict the future of endoscopy, but it certainly is exciting.

\section{Competing interests}

None

\section{References}

[1] Garbin N, Dennis S, Ryan H et al. Evaluation of a novel low-cost disposable endoscope for visual assessment of the esophagus and 
stomach in an ex-vivo phantom model. Endoscop Int Open 2019; 07: E1175-E1183

[2] Fried GM, Marks JM, Mellinger JD et al. ASGE's assessment of competency in endoscopy evaluation tools for colonoscopy and EGD. Gastrointest Endosc 2014; 80: 366 - 367

[3] Beilenhoff U, Biering H, Blum R et al. Reprocessing of flexible endoscopes and endoscopic accessories used in gastrointestinal endoscopy: Position Statement of the European Society of Gastrointestinal Endoscopy (ESGE) and European Society of Gastroenterology Nurses and Associates (ESGENA) - Update 2018. Endoscopy 2018: 50

[4] Ofstead CL, Quick MR, Eiland JE et al. A glimpse at the true cost of reprocessing endoscopces: results of a pilot project. Available at: https://www.bostonscientific.com/content/dam/bostonscientific/ uro-wh/portfolio-group/LithoVue/pdfs/Sterilization-Resource-Handout.pdf

[5] Crews NR, Gorospe EC, Johnson ML et al. Comparative quality assessment of esophageal examination with transnasal and sedated endoscopy. Endosc Int Open 2017; 05: E340-E344

[6] Kang D, Lim CH, Choi MG et al. An operable, portable, and disposable ultrathin endoscope for evaluation of the upper gastrointestinal tract. Dig Dis Sci 2019: doi:10.1007/s10620-019-5478-0

[7] PrimeSight customer advisory. Cogentix Medical; Available at: https://www.cogentixmedical.com/discontinued-primesight-pro-
ducts?hsCtaTracking=bf37285b-dd34-4774-a178-5a75581ca7fb\% 7C341c2ece-e577-4c69-bf9f-7d1e33d3d424

[8] The future of endoscopy starts now - sterile single-use endoscopy. Ambu Inc; Available at: https://www.ambu.com/Files/Files/Ambu/ Investor/News/English/2018/The_Future_of_Endoscopy_(screen_ view).pdf

[9] Gluck N, Melhem A, Halpern Z et al. A novel self-propelled disposable colonoscope is effective for colonoscopy in humans (with video). Gastrointest Endosc 2016; 83: 998 - 1004.e1

[10] Tumino E, Parisi G, Bertoni M et al. Use of robotic colonoscopy in patients with previous incomplete colonoscopy. Eur Rev Med Pharmacol Sci 2017; 21: 819-826

[11] Groth S, Rex DK, Rösch T et al. High cecal intubation rates with a new computer-assisted colonoscope: a feasibility study. Am J Gastroenterol 2011; 106: 1075-1080

[12] Schwabl P, Leibmann BKöppel S et al. Assessment of microplastic concentrations in human stool. Available at: http://www.umweltbundesamt.at/fileadmin/site/presse/news_2018/UEG_Week_2018__Philipp_Schwabl_Microplastics_Web.pdf

[13] European Commission. European parliament votes for single-use plastics ban. Environ Euro; 2019: Available at: https://ec.europa.eu/ environment/efe/content/european-parliament-votes-single-useplastics-ban_en 